\title{
Influence of Different Classes of Insecticides on Honey Bee Survival
}

\author{
Saffet Sansar ${ }^{1, *}$ \\ ${ }^{1}$ Apiculture Research Institute Directorate, Ordu, Turkey
}

\section{Article History}

Received 16 November 2021

Accepted 14 December 2021

First Online 28 December 2021

\section{* Corresponding Author}

Tel.: +905454629144

E-mail: saffet.snsr@gmail.com

\section{Keywords}

Honey bee

Carbon microparticles

Pesticides

\begin{abstract}
Pesticides used to prevent or control unwanted pests are often being considered as a cause of the decline of the honey bee (Apis mellifera) population. Exposure to insecticides, or a group of pesticides, has many negative effects on honey bees. Here we elucidated whether feeding carbon microparticles, designed to absorb pesticide residues, improved to the survival of honey bees exposed to pesticides. Honey bees were exposed to different classes of insecticides (thiamethoxam, chlorpyrifos, and carbaryl) for 10 days. The study shows that feeding carbon microparticles didn't ameliorate the survival of honey bees exposed to insecticidal compounds.
\end{abstract}

\section{Introduction}

Pesticides are an indispensable part of modern agriculture because of their role in reducing pest numbers, improving yields, and quality of the crops (Damalas \& Eleftherohorinos, 2011). However, the extensive use of pesticides in agricultural areas is a major concern for honey bees that are integral for pollination service a wide variety of plants (vanEngelsdorp \& Meixner, 2010). Since forager bees visit many pesticide treated crops to gather pollen and nectar, more than one hundred different residues of pesticides including miticides, insecticides, fungicides, and herbicides have been identified in hive products (Mullin et al., 2010). Such exposure to pesticides is a well-known factor that causes colony health problems and leads to population decline or loss (Doublet et al., 2015; Schneider et al., 2012; Urlacher et al., 2016; Yang et al., 2008)

Insecticides are the main risk group of pesticides to honey bees. In modern agriculture, different classes of insecticides including organophosphates, neonicotinoids, and carbamate have been using against target organisms and each class has a different mode of action on honey bees. These insecticides used to control insect pests do not only affect the target organism but can also affect numerous beneficial insects, such as the honey bee, when exposed to these insecticides in treated fields.

Mitigating the exposure to pesticides is important, but unintended sublethal exposure also poses a risk for honey bees. Therefore, we investigated the functionality of a newly developed carbon microparticle materials that was designed with the goal to adsorb ingested pesticide residues for the purpose of protecting bees. The carbon microparticles can be mixed into the sugar syrup used to feed honey bee colonies (US Fed News Service, 2018).

The goal of this study was to determine the effects of carbon microparticle on honey bee survival while exposing bees to three widely used insecticides. Our study revealed carbon microparticle food did not negatively or positively affect honey bee survival under pesticide exposure during laboratory experiment.

\section{Materials and Methods}

\section{Chemicals}

Thiamethoxam (THX), Chlorpyrifos ( $\mathrm{CHL})$, and Carbaryl (CRB) (all insecticides 99\% purity) were purchased from Sigma-Aldrich (Missouri, United 
States). Initially, the powder form of each insecticide was solved in acetone $(40 \mathrm{mg} / \mathrm{L})$ to prepare a stock solution. Then the stock solutions were diluted into $50 \%$ $\mathrm{W} / \mathrm{V}$ sugar syrup to a final concentration of $40 \mu \mathrm{g} / \mathrm{L}$. The percentage of stock solution in the syrup was equal to $0.1 \%(V / V)$.

\section{Experimental design of laboratory exposures}

Unknown age worker honey bees were collected from frames of a colony located in a WSU apiary site in Pullman, WA and transported to the laboratory. Worker bees were randomly distributed into plastic cages (14 x $18.1 \times 11.1 \mathrm{~cm}$ ) containing approximately 70 bees each cage. The cages were held in an incubator at $27 \pm 2{ }^{\circ} \mathrm{C}$ and $70 \%$ relative humidity during the experiment.

Honey bees in cages were subjected to one of eight treatments over 10 days. Each treatment group was comprised of three replicate cages. Two of the groups were treated as controls, with one group fed just sugar syrup ( $50 \% \mathrm{~W} / \mathrm{V})$ and the other was fed syrup containing $0.1 \%$ carbon microparticles. Three of the groups (TXM, $\mathrm{CHL}$, and CRB) were fed the syrup (50\% W/V) at first for 12 hours and then the feeders in the cages were swapped with the feeders containing $40 \mathrm{\mu g} / \mathrm{L}$ thiamethoxam, chlorpyrifos, and carbaryl for 12 hours. Feeder swapping was repeated over 10 days for each 12 hours period. As for $\mathrm{CM}$ treatments, unlike the previous three groups, these three groups (CM/TXM, CM/CHL, and $\mathrm{CM} / \mathrm{CRB}$ ) were fed with syrup containing $0.1 \% \mathrm{CM}$ at first for $12 \mathrm{~h}$ period. Then, the groups were fed the syrup containing $40 \mu \mathrm{g} / \mathrm{L}$ thiamethoxam, chlorpyrifos, and carbaryl for $12 \mathrm{~h}$ period until the next feeder change during the experiment. Feeders in the cages were measured to estimate average consumption of the syrup for per bee for the last five days of experiment. Dead bees in the cages were counted every day for 10 days.

\section{Statistical analysis}

Analyses were conducted in the online application for survival analysis (OASIS 2) program. The 10 day honey bee survival data among groups were analyzed using Kaplan-Meier survival analysis. Differences between survival curves of treatment and control groups were determined using Log-Rank test. The gallic acid equivalent of bee pollen samples was calculated using the gallic acid curve (Saroglu, 2018).

\section{Results}

In this experiment, We recorded the survival of honey bees fed with $\mathrm{CM}$ food while exposing them to three different insecticides (Thiamethoxam, Chlorpyrifos, and Carbaryl). The percent survival in the control and $\mathrm{CM} /$ control groups were $84.30 \%$ and $78.57 \%$, respectively over 10 days (Figure 1 ). There was no significant difference between the survival of control and $\mathrm{CM} /$ control $(P>0.05$ by log-rank test) (Table 1$)$.

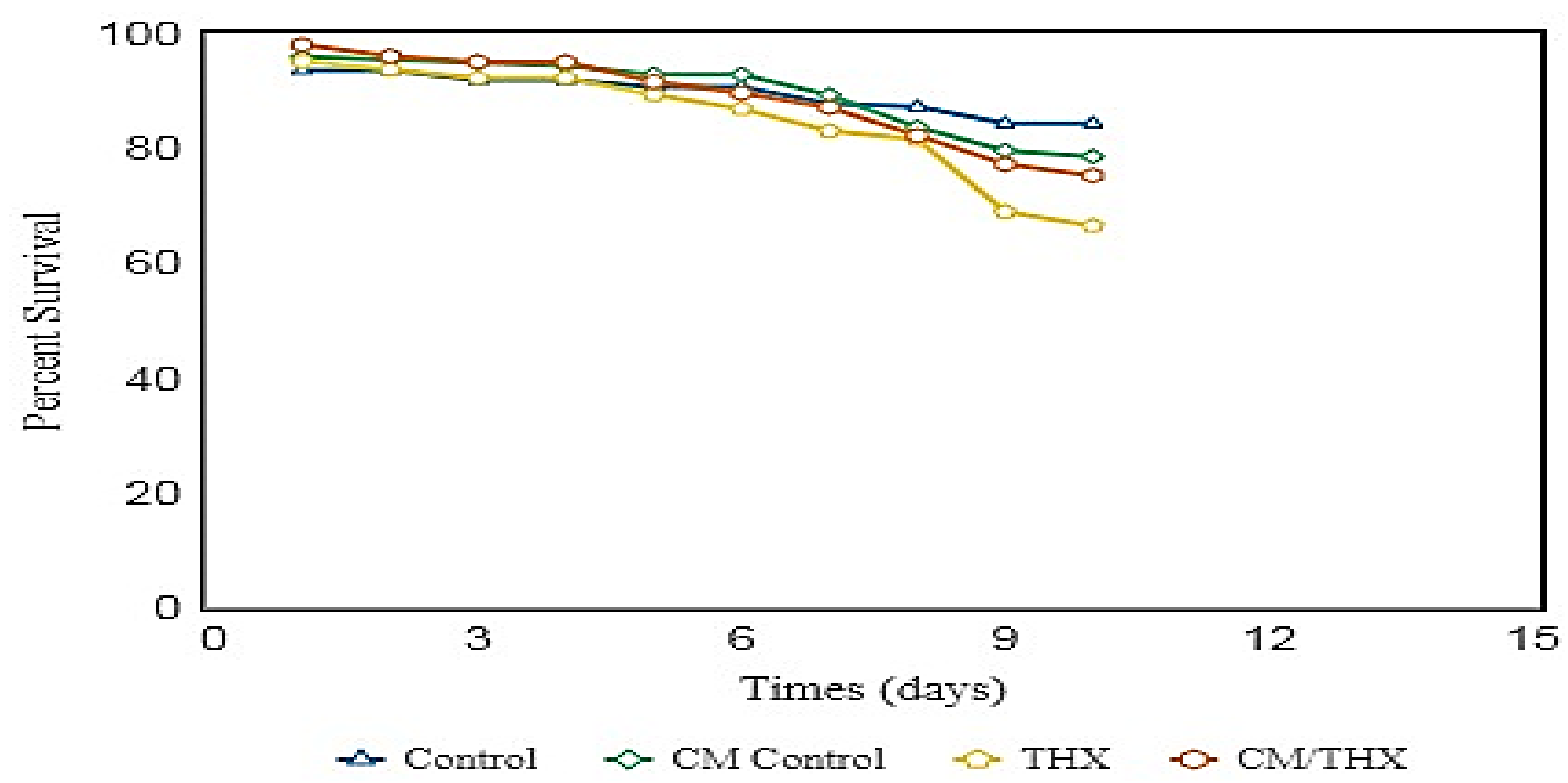

Control: Group of honey bees fed without carbon microparticles. CM Control: Group of honey bees fed with carbon microparticles. THX: Group of honey bees exposed to thiamethoxam and fed without carbon microparticles. CM/THX: Group of honey bees exposed to thiamethoxam and fed with carbon microparticles.

Figure 1. Honey bee survival ratio comparisons between the control groups and treatment groups exposed to thiamethoxam. 
Table 1. Survival analysis between groups treated with and without carbon microparticles by Kaplan-Meier Procedure.

\begin{tabular}{lcccccc}
\hline & $\mathbf{n}$ & $\begin{array}{c}\text { Survival (\%) } \\
\text { at 10 d }\end{array}$ & Mean & S.E. & $95 \%$ Cl & $\begin{array}{c}P \\
\text { (Log -Rank) }\end{array}$ \\
\hline Control & 172 & 84.30 & 9.12 & 0.18 & $8.75-9.16$ & 1 \\
CM/Control & 196 & 78.57 & 9.19 & 0.15 & $8.90-9.48$ \\
THX & 206 & 66.50 & 8.83 & 0.17 & $8.50-9.16$ & 0.86 \\
CM/THX & 202 & 75.24 & 9.12 & 0.14 & $8.84-9.40$ & 0.27 \\
CHL & 232 & 79.74 & 9.01 & 0.16 & $8.69-9.63$ & $8.76-9.31$ \\
CM/ CHL & 251 & 75.29 & 9.04 & 0.14 & $7.80-8.53$ & 0.17 \\
CRB & 210 & 49.04 & 8.17 & 8.51 & 0.19 & $8.19-8.83$
\end{tabular}

Control: Group of honey bees fed without carbon microparticles. CM/Control: Group of honey bees fed with carbon microparticles. THX: Group of honey bees exposed to thiamethoxam and fed without carbon microparticles. CM/THX: Group of honey bees exposed to thiamethoxam and fed with carbon microparticles. CHL: Group of honey bees exposed to chlorpyrifos and fed without carbon microparticles. CM/CHL: Group of honey bees exposed to chlorpyrifos and fed with carbon microparticles. CRB: Group of honey bees exposed to carbaryl and fed without carbon microparticles. CM/CRB: Group of honey bees exposed to carbaryl and fed with carbon microparticles.

The average consumption of the syrup was 0.056 and $0.052 \mathrm{~mL} /$ bee day for the control and $\mathrm{CM} /$ control group respectively. The average consumption of the syrup containing insecticides among other groups ranged from 0.045 to $0.061 \mathrm{~mL} /$ bee day in the experiment. Based on the consumption of syrup including insecticides, We could estimate the consumption over the last 5 days per bee. Average consumption of insecticides for each treatment per day were: CRB: $0.0018 \mu \mathrm{g} / \mathrm{bee}$; THX: $0.0021 \mu \mathrm{g} / \mathrm{bee}$; $\mathrm{CHL}$ : $0.0016 \mu \mathrm{g} / \mathrm{bee} ; \mathrm{CM} / \mathrm{CRB}: 0.0015 \mu \mathrm{g} / \mathrm{bee}$; CM/THX: $0.0022 \mu \mathrm{g} / \mathrm{bee} ; \mathrm{CM} / \mathrm{CHL} \mu \mathrm{g} /$ bee: $0.0024 \mu \mathrm{g} / \mathrm{bee}$.

When exposed to thiamethoxam $(40 \mu \mathrm{g} / \mathrm{L})$, the percentage of survival of groups exposed to THX syrup and pre fed CM prior to exposure to THX was $66.50 \%$ and $75.24 \%$, respectively (Figure 1 ). The survival of THX and CM/THX did not differ significantly from each other ( $P>0.05$ by log-rank test) (Table 1$)$. However, the survival analysis indicated that exposure to thiamethoxam induced a significant decrease in honey bee survival compared to the control group of honey bees $(P<0.05$ by log-rank test) (Table 2).

The groups (CRB and CM/CRB) exposed to carbaryl $(40 \mu \mathrm{g} / \mathrm{L})$ showed the lowest survival at the rate of $49.04 \%$ and $53.72 \%$, respectively (Figure 3 ). The survival of bees exposed to carbaryl demonstrated a noticeable reduction in survival compared to the control group $(P<0.05$ by log-rank test) (Table 2$)$. However, the survival between groups CRB and CM/CRB did not significantly differ considerably from each other $(P>0.05$ by log-rank test) (Table 1 and Table 3).

The survival of the bees exposed to chlorpyrifos (40 $\mu \mathrm{g} / \mathrm{L}$ ) was $79.74 \%$ and $75.29 \%$ for group $\mathrm{CHL}$ and
$\mathrm{CM} / \mathrm{CHL}$ respectively after 10 days (Figure 2 ). Similarly, there was no significant difference in the survival of between-group $\mathrm{CHL}$ and $\mathrm{CM} / \mathrm{CHL}(P<0.05$ by log-rank test) (Table 1 and Table 3). Contrary to thiamethoxam and carbaryl, the exposure to chlorpyrifos did not significantly change the survival of both groups compared to control group $(P<0.05$ by log-rank test) (Table 1).

\section{Discussion}

The survival of honey bees when feeding small doses of insecticides varied, likely a reflection of the fact that LD50 values also differ for each of the tested insecticides. The oral LD50 value of carbaryl, thiamethoxam, and chlorpyrifos is $0.15,0.005$, and 0.24 $\mu \mathrm{g} /$ bee, respectively, and all of them are highly toxic to bees (Sanchez-Bayo \& Goka, 2014). Our concentrations of the insecticides was lower than these LD50 concentrations. However, the exposure to low level or sublethal doses of pesticides may cause stress that makes the bee colony weak and susceptible to pathogenic infection and can also reduce the lifespan of foragers (Pettis et al., 2012; Vidau et al., 2011; Wu et al., 2011).

The survival of $\mathrm{CM}+$ and $\mathrm{CM}$ - groups exposed to thiamethoxam, carbaryl, and chlorpyrifos showed a similar decline for 10 days. Therefore, feeding honey bees with carbon microparticles did not mitigate bee mortality during exposure to the insecticides. In addition, feeding honey bees with sugar syrup containing carbon microparticles did not negatively impact survival during the experiment. 
The survival of honey bees was significantly reduced by carbaryl at a concentration of $40 \mu \mathrm{g} / \mathrm{L}$ for 10 days (Figures 3 ). In the experiment, the cumulative oral dose of carbaryl for 10 days was estimated at 0.018 $\mu \mathrm{g} /$ bee; eight times lower than the reported LD50 values (Sanchez-Bayo \& Goka, 2014). Although our concentration was less toxic to honey bees, approximately half of the group was dead after 10 days. Such a high number of dead bees might have been due to physical contact. A previous study has been demonstrated that body contact with the carbaryl killed more bees than oral contact (Tarek et al., 2018).

Table 2. Survival analysis between control and treatment groups exposed to different pesticides by Kaplan-Meier Procedure.

\begin{tabular}{lcccccc}
\hline & $\mathbf{n}$ & $\begin{array}{c}\text { Survival (\%) } \\
\text { at 10 d }\end{array}$ & Mean & S.E. & 95\% Cl & $\begin{array}{c}\boldsymbol{P} \\
\text { (Log -Rank) }\end{array}$ \\
\hline Control & 172 & 84.30 & 9.12 & 0.18 & $8.75-9.16$ & 0.0002 \\
THX & 196 & 66.50 & 8.83 & 0.17 & $8.50-9.16$ & 0.26 \\
Control & 172 & 84.30 & 9.12 & 0.18 & $8.75-9.16$ & 0 \\
CHL & 232 & 79.74 & 9.01 & 0.16 & $8.69-9.33$ & 0.18 \\
Control & 172 & 84.30 & 9.12 & $8.75-9.16$ & 0.16 \\
CRB & 210 & 49.04 & 8.17 & 0.19 & $7.80-8.53$ & \\
\hline
\end{tabular}

Control: Group of honey bees fed without carbon microparticles. THX: Group of honey bees exposed to thiamethoxam and fed without carbon microparticles. CHL: Group of honey bees exposed to chlorpyrifos and fed without carbon microparticles. CRB: Group of honey bees exposed to carbaryl and fed without carbon microparticles.

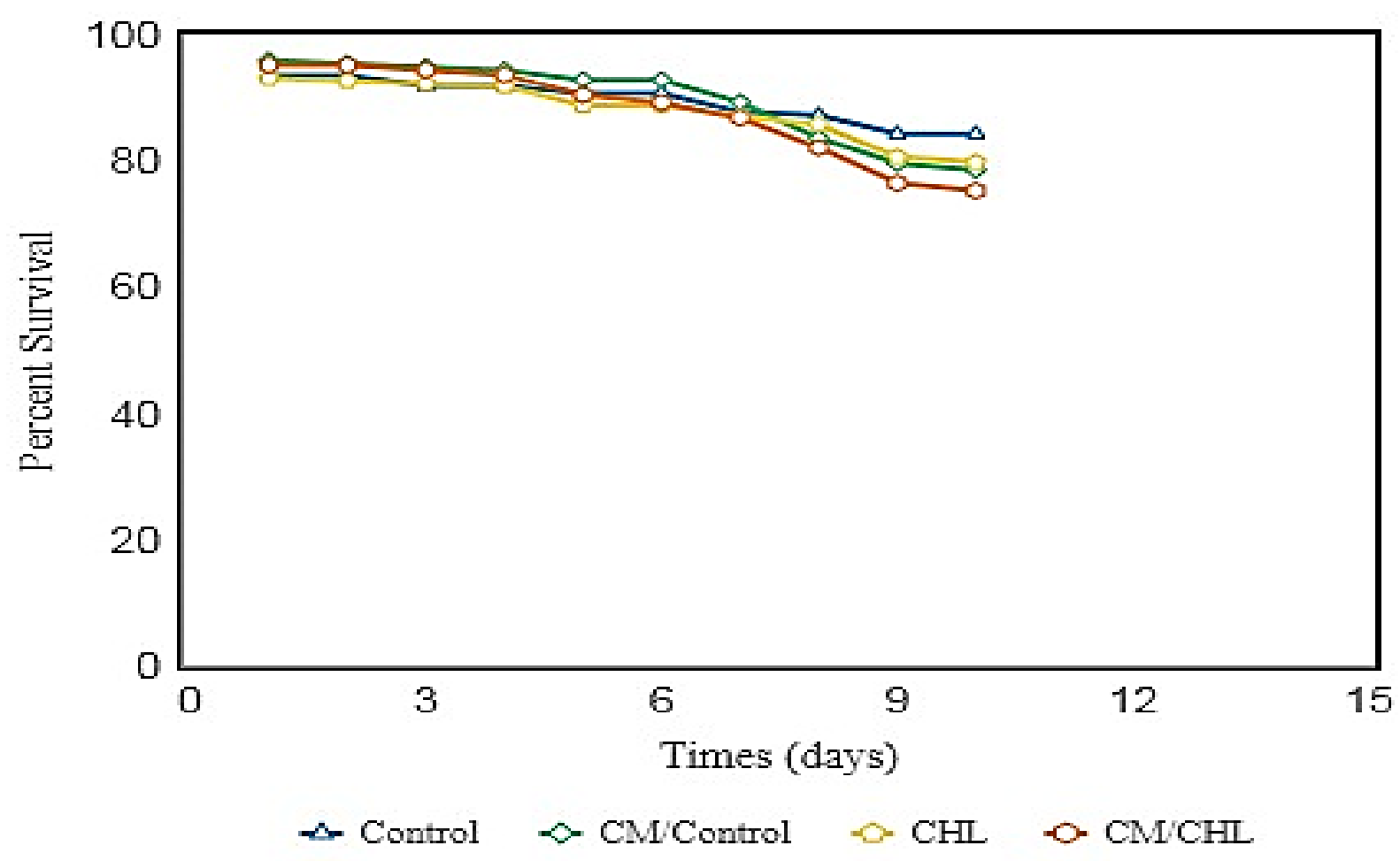

CHL: Group of honey bees exposed to chlorpyrifos and fed without carbon microparticles. $\mathrm{CM} / \mathrm{CHL}$ : Group of honey bees exposed to chlorpyrifos and fed with carbon microparticles.

Figure 2. Honey bee survival ratio comparisons between the control groups and treatment groups exposed to chlorpyrifos. 
Therefore, bees inside the cage might have external contact with the carbaryl and, consequently, a higher percentage of dead bees for the 10 day exposure.

It has been reported that a concentration of 100 $\mu \mathrm{g} / \mathrm{L}$ thiamethoxam causes acute effects for individual bees (Overmyer et al., 2018). However, in the present study, exposure to the lower concentration of thiamethoxam $(40 \mu \mathrm{g} / \mathrm{L})$ caused a significant decline in the honey bee survival (66\%) over 10 days (Figure 1). A constant exposure to the low dose of thiamethoxam over time may have led to increased bee mortality.

The acute of oral toxicity LD50 values at 24 hours for thiamethoxam was $4.4-4.7 \mathrm{ng} / \mathrm{bee}$ (Laurino et al., 2011; 2013). The estimated exposure to thiamethoxam for 10 days in my experiment was $21 \mathrm{ng} / \mathrm{bee}$, which is about four-fold higher than the documented 24-hour LD50 concentration and led to $34 \%$ of the honey bees dying during the experiment. The estimated "daily" exposure rate would be $2.1 \mathrm{ng} /$ bee in the current study, about half of the 24-hour LD50 value. Laurino et al. (2011; 2013) used a commercial formulation of thiamethoxam (Actara ${ }^{\circledR}$ : $25.0 \%$ pure a.s., hydro dispersible granules) in their experiment but it was used thiamethoxam (Sigma-Aldrich) with a purity of $99 \%$ in this experiment. Commercial pesticides may include chemical adjuvants that are harmful to bees and increase the toxicity of pesticides to honey bees (Chen et al., 2019). Therefore, the same concentration of thiamethoxam used in this study might be less toxic to honey bees than previous studies utilizing commercial formulations.
In contrast to carbaryl and thiamethoxam, chlorpyrifos insecticide showed no reduction in honey bee survival in this experiment. Chlorpyrifos has the least toxic LD50 value $(0.24 \mu \mathrm{g} / \mathrm{bee})$ of the three insecticides used in this study, although it is still considered highly toxic to bees (Sanchez-Bayo \& Goka, 2014). In our experiment, the estimated cumulative dose of chlorpyrifos for 10 days was around 0.020 $\mu \mathrm{g} /$ bee. The amount of active ingredient delivered daily to the bees was, therefore, approximately 12 times less than the published LD50 value. Such a low concentration of chlorpyrifos might not lead to a measurable reduction in honey bee survival. Although our concentration of chlorpyrifos did not reduce honey bee survival, exposure to chlorpyrifos to amounts 10-times lower than the LD50 values has been shown to have a negative impact on the immune system of honey bees (Christen \& Fent, 2017).

In summary, pesticide toxins in plants and hive products are a major risk for honey bee colonies. This study focused on the survival of honey bees exposed to three insecticides fed with and without carbon microparticles. Carbon microparticles did not affect the survival of honey bees after exposure to putatively sublethal amounts of the three insecticides tested. Further studies may be warranted to better understand how feeding carbon microparticles impact honey bees exposed to insecticides.

Table 3. Survival analysis between control group fed with carbon microparticles and treatment groups exposed to different pesticides by Kaplan-Meier Procedure.

\begin{tabular}{|c|c|c|c|c|c|c|}
\hline & $\mathbf{n}$ & $\begin{array}{c}\text { Survival (\%) } \\
\text { at } 10 \mathrm{~d}\end{array}$ & Mean & S.E. & $95 \% \mathrm{Cl}$ & $\begin{array}{c}P \\
(\log -\text { Rank) }\end{array}$ \\
\hline $\mathrm{CM} /$ Control & 196 & 78.57 & 9.19 & 0.15 & $8.90-9.48$ & 0.44 \\
\hline CM/THX & 202 & 75.24 & 9.12 & 0.14 & $8.84-9.40$ & \\
\hline $\mathrm{CM} /$ Control & 196 & 78.57 & 9.19 & 0.15 & $8.90-9.48$ & 0.41 \\
\hline $\mathrm{CM} / \mathrm{CHL}$ & 251 & 75.29 & 9.04 & 0.14 & $8.76-9.31$ & \\
\hline $\mathrm{CM} /$ Control & 196 & 78.57 & 9.19 & 0.15 & $8.90-9.48$ & $1.6 e-7$ \\
\hline CM/CRB & 255 & 53.72 & 8.51 & 0.16 & 8.19-8.83 & \\
\hline
\end{tabular}

CM/Control: Group of honey bees fed with carbon microparticles. CM/THX: Group of honey bees exposed to thiamethoxam and fed with carbon microparticles. $\mathrm{CM} / \mathrm{CHL}$ : Group of honey bees exposed to chlorpyrifos and fed with carbon microparticles. CM/CRB: Group of honey bees exposed to carbaryl and fed with carbon microparticles. 


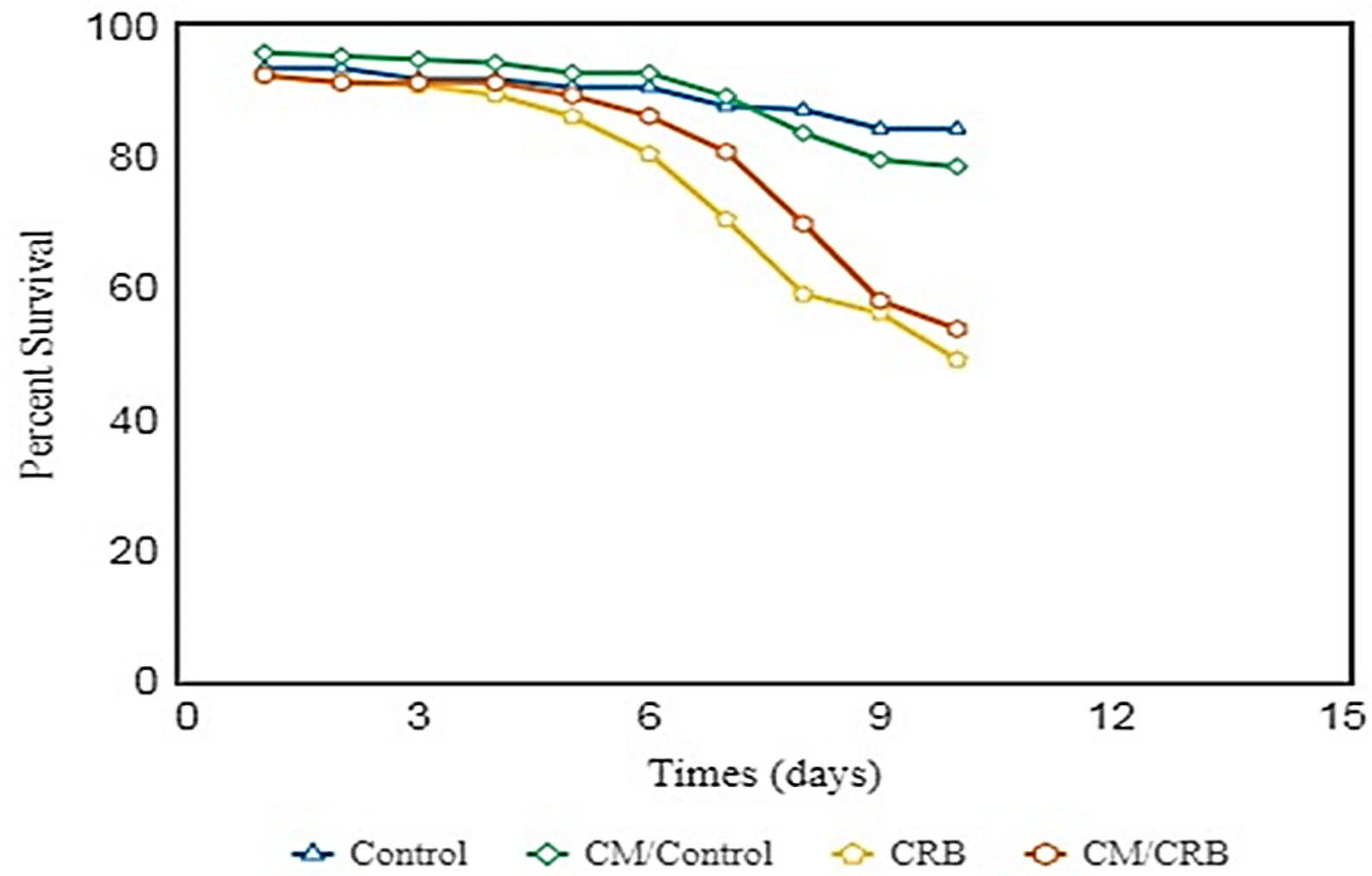

CRB: Group of honey bees exposed to carbaryl and fed without carbon microparticles. CM/CRB: Group of honey bees exposed to carbaryl and fed with carbon microparticles.

Figure 3. Honey bee survival ratio comparisons between the control groups and treatment groups exposed to carbaryl for 10 days.

\section{Conclusion}

Exposure to pesticides is a major concern for honey bee health. However, the use of pesticides is considered widely necessary because they enhance productivity, protect against crop losses, provide vector disease control and assure quality food for humans (Aktar et al., 2009). Concern about the hazar of pesticide use on honey bees has led to investigating new method for researchers to minimize pesticide impact. Feeding honey bee colonies with carbon microparticles might protect honey bees against exposure to pesticides.

The study has shown that feeding honey bees with carbon microparticles didn't affect their survival when they exposed to thiamethoxam (THX), chlorpyrifos ( $\mathrm{CHL}$ ), and carbaryl (CRB) for ten days. The survival of honey bees between $\mathrm{CM}+$ and $\mathrm{CM}$ - groups demosrated similarities for 10 days. Additional studies are required for a better understanding whether carbon microparticles could protect honey bees exposed to pesticides.

\section{Acknowledgement}

This study is a part of the MSc thesis and supported by Washington State University. I would like to express my deep sense of gratitude to my advisor Professor Dr. Sheppard and Dr. Hopkins for their support and guidance during my master education. I would also like to thank each member of the WSU Honey Bee Lab for giving their experiences, ideas and invaluable time to enable me to finish this research.

\section{References}

Aktar, M. W., Sengupta, D., \& Chowdhury, A. (2009). Impact of pesticides use in agriculture: Their benefits and hazards. Interdisciplinary Toxicology, 2(1), 1-12. https://doi.org/10.2478/v10102-009-0001-7

Chen, L., Yan, Q., Zhang, J., Yuan, S., \& Liu, X. (2019). Joint toxicity of acetamiprid and co-applied pesticide adjuvants on honeybees under semifield and laboratory conditions. Environmental Toxicology and Chemistry, 38(9), 19401946. https://doi.org/10.1002/etc. 4515 
Christen, V., \& Fent, K. (2017). Exposure of honey bees (Apis mellifera) to different classes of insecticides exhibit distinct molecular effect patterns at concentrations that mimic environmental contamination. Environmental Pollution (Barking, Essex: 1987), 226, 48-59. https://doi.org/10.1016/j.envpol.2017.04.003

Damalas, C. A., \& Eleftherohorinos, I. G. (2011). Pesticide exposure, safety Issues, and risk assessment Indicators. International Journal of Environmental Research and Public Health, 8(5), 1402-1419. https://doi.org/10.3390/ijerph8051402

Doublet, V., Labarussias, M., de Miranda, J. R., Moritz, R. F. A., \& Paxton, R. J. (2015). Bees under stress: Sublethal doses of a neonicotinoid pesticide and pathogens interact to elevate honey bee mortality across the life cycle. Environmental Microbiology, 17(4), 969-983.

https://doi.org/10.1111/1462-2920.12426

Laurino, D., Manino, A., Patetta, A., \& Porporato, M. (2013). Toxicity of neonicotinoid insecticides on different honey bee genotypes. Bulletin of Insectology, 66, 119-126.

Laurino, D., Porporato, M., Patetta, A., Manino, A., \& Va, D. (2011). Toxicity of neonicotinoid insecticides to honey bees: Laboratory tests. Bulletin of Insectology, 64, 107-113.

Mullin, C. A., Frazier, M., Frazier, J. L., Ashcraft, S., Simonds, R., vanEngelsdorp, D., \& Pettis, J. S. (2010). High Levels of Miticides and Agrochemicals in North American Apiaries: Implications for Honey Bee Health. PLOS ONE, 5(3), e9754. https://doi.org/10.1371/journal.pone.0009754

Overmyer, J., Feken, M., Ruddle, N., Bocksch, S., Hill, M., \& Thompson, H. (2018). Thiamethoxam honey bee colony feeding study: Linking effects at the level of the individual to those at the colony level. Environmental Toxicology and Chemistry, 37(3), 816-828. https://doi.org/10.1002/etc.4018

Pettis, J., VanEngelsdorp, D., Johnson, J., \& Dively, G. (2012). Pesticide exposure in honey bees results in Increased levels of the gut pathogen Nosema. Die Naturwissenschaften, 99, 153-158. https://doi.org/10.1007/s00114-011-0881-1

Sanchez-Bayo, F., \& Goka, K. (2014). Pesticide residues and bees - A risk assessment. PLOS ONE, 9(4), e94482. https://doi.org/10.1371/journal.pone.0094482

Schneider, C. W., Tautz, J., Grünewald, B., \& Fuchs, S. (2012). RFID tracking of sublethal effects of two neonicotinoid Insecticides on the foraging behavior of Apis mellifera.
PLOS ONE, 7(1), e30023.

https://doi.org/10.1371/journal.pone.0030023

Tarek, H., Hamiduzzaman, M. M., Morfin, N., \& Guzman-Novoa, E. (2018). Sub-lethal doses of neonicotinoid and carbamate insecticides reduce the lifespan and alter the expression of immune health and detoxification related genes of honey bees (Apis mellifera). Genetics and Molecular Research, 17(2).https://doi.org/10.4238/gmr16039908

Urlacher, E., Monchanin, C., Rivière, C., Richard, F.-J., Lombardi, C., Michelsen-Heath, S., Hageman, K. J., \& Mercer, A. R. (2016) Measurements of chlorpyrifos levels in forager bees and comparison with levels that disrupt honey bee odormediated learning under laboratory conditions. Journal of Chemical Ecology, 42(2), 127-138. https://doi.org/10.1007/s10886-016-0672-4

US Fed News Service.(2018).Researchers create microparticles that could help save honey bees. US Fed News Service, Including US State News, p. US Fed News Service, Including US State News, Apr 11, 2018.

vanEngelsdorp, D., \& Meixner, M. D. (2010). A historical review of managed honey bee populations in Europe and the United States and the factors that may affect them. Journal of Invertebrate Pathology, 103, S80-595. https://doi.org/10.1016/j.jip.2009.06.011

Vidau, C., Diogon, M., Aufauvre, J., Fontbonne, R., Viguès, B., Brunet, J.-L., Texier, C., Biron, D. G., Blot, N., Alaoui, H. E., Belzunces, L. P., \& Delbac, F. (2011). Exposure to sublethal doses of fipronil and thiacloprid highly increases mortality of honeybees previously infected by Nosema ceranae. PLOS ONE, 6(6), e21550. https://doi.org/10.1371/journal.pone.0021550

Wu, J. Y., Anelli, C. M., \& Sheppard, W. S. (2011). Sub-lethal effects of pesticide residues in brood comb on worker honey bee (Apis mellifera) development and longevity. PLOS ONE, 6(2), e14720. https://doi.org/10.1371/journal.pone.0014720

Yang, E. C., Chuang, Y. C., Chen, Y. L., \& Chang, L. H. (2008). Abnormal foraging behavior induced by sublethal dosage of imidacloprid in the honey bee (Hymenoptera: Apidae). Journal of Economic Entomology, 101(6), 1743-1748. https://doi.org/10.1603/0022-0493-101.6.1743 